\title{
Is it better to die than to be lonely?
}

In a sophisticated student essay, Isabelle L Robertson considers the possibility of using germline editing to extend the human lifespan. There is a longstanding debate in the bioethics and enhancement literature about the ethics of human lifespan extension, but much of this debate is in fairly abstract terms, in that the ethics tend not to depend very much on exactly how lifespan extension is achieved. Robertson's contribution is to argue that it can matter very much how we extend the human lifespan, and that doing so by editing the human genome would be unethical.

Robertson notes that an intervention that enabled people to live 'a full generation longer (15-25 years) than those in the same birth cohort', even if safe, would not be an unmitigated good. In the elderly, loneliness is linked to a number of risks to physical and mental health, and outliving one's peers contributes to loneliness. People with enhanced lifespans, if in a relatively small minority, can be expected to outlive more of their peers and for longer, and so to experience a significantly reduced quality of life in their later years. For an individual weighing up whether or not to extend their own lifespan using drugs, this need not present a problem: one could choose to extend one's life if one thinks the benefits of doing so outweigh the drawbacks, otherwise one could abstain. Extending lifespan through germline genetic editing, however, would take place when the human whose lifespan is to be extended is an embryo. As such, the subject is not able to choose whether or not to extend her own lifespan, taking into account the benefits and drawbacks of doing so. Extending someone's lifespan in this way commits her to all the good and bad that a longer life entails, whether she likes it or not. Because of this, Robertson concludes that lifespan extension through germline editing would be unethical.

I want to highlight two concerns with this line of reasoning. The first is that, even if one suffers by outliving those with whom one has valuable social connections, it is far from obvious that the extent

Correspondence to Dr Rebecca Roache, Department of Philosophy, Royal Holloway, University of London, Egham, Surrey TW20 OEX, UK;

rebecca.roache@royalholloway.ac.uk of this suffering is such that it would be better to die than to experience it. The second is that Robertson's argument that it is unethical to extend lifespan through germline editing is far less persuasive when applied to therapeutic uses, so the view that it is unethical when it involves enhancement relies on a controversial claim about the ethical significance of the distinction between therapy and enhancement.

First, to keep things simple, suppose we could be fairly certain that extending someone's life by editing their germline would result in late-life loneliness and its consequent health problems. (In reality, there would be room for doubt about this.) In that case, in deciding whether or not to bring into being a person whose genome has been edited to increase their life expectancy, the drawbacks of a lifespan that is greater than that of their peers is indeed ethically significant. It is widely acknowledged-including in the debates about euthanasia, end-of-life care and the allocation of scarce resources such as organs for transplantationthat a longer life of lower quality is not always better than a shorter life of greater quality, nor is it a simple matter to gauge how many years of higher quality life are equal in value to some (greater) number of years of lower quality life. Even so, comparing the life of a person whose life has been extended by germline editing to the otherwise similar life of a person whose life has not been extended in this way is not like comparing a longer, lowerquality life to a shorter, higher-quality one. Imagine that, in the community we are considering, average life expectancy is 75 years. Thanks to germline editing, a member of this community can expect to live until they are between 90 and 100 . Other things being equal, the enhanced person and her unenhanced peers have lives of comparable quality for around 75 years, after which the unenhanced peers die and the enhanced person lives a further 15-25 years of reduced quality life. Unless these additional years are so bad that the enhanced person would be better off dead-as would be the case were she in excruciating pain, for example-the enhanced person does not end up worse off for her enhancement. As long as her extra years are of sufficiently high quality for her to be better off alive than dead, she is better off for her enhancement. Since we do not currently view elderly people as generally having lives of such low quality that they would be better off dead than alive, even the prospect of late-life loneliness does not give us sufficient reason to believe that one might harm a person by extending their lifespan and condemning them to late-life loneliness, rather than allowing them to die 20 years or so earlier. Only if the subject's extra years can be expected to be worse than death would extending her lifespan through editing her germline be clearly unethical. Robertson gives us reason to believe that the later years of extended life would, other things being equal, be lower in quality than the preceding years, but she does not give us reason to believe that the additional years would be worse than death.

Second, I suspect that concerns about the ethics of lifespan extension through germline editing are likely to be more deeply felt when the extension in question is viewed as an enhancement of lifespan-that is, when it proposes to increase lifespan above and beyond what is considered healthy or normal-than when it is therapeutic, or aimed at curing a lifespan-shortening disease. Consider the following imaginary scenario. Huntington's disease is an inherited, currently incurable disorder, the symptoms of which typically appear in middle age. Life expectancy after diagnosis is $15-20$ years. Suppose that scientists find a way to use germline editing to correct the genetic defect that causes Huntington's. People who develop from edited embryos, who would otherwise have suffered from Huntington's later in life, will be free of the disease. Assuming that such a technique would not carry any significant medical risks, it would be a wonderful medical advance. It would enable people currently suffering from, or carrying, Huntington's disease to ensure that they would not pass the disease to their children. Suppose, however, that there exists an isolated community of people who all have Huntington's disease. Before their symptoms begin to appear, people in this community have lives comparable in quality to those typical of people in 
first-world countries, but they all tend to die at around age 50. Would it be ethical for aspiring parents in this community to use the technology just described to ensure that they do not pass Huntingdon's disease to their children? Following Robertson's reasoning, while such an intervention may be ethical in communities in which Huntington's is relatively rare, there would be a problem with using it in a community of people who all suffer from Huntington's. This is because, unless this technology is widely adopted from the outset, people born without Huntington's in this community could expect to live significantly longer than their peers; as a result, in their later years they would suffer from loneliness and its associated health problems.

It is unlikely that we would think it unethical for aspiring parents in this community to use the intervention to ensure that their children were born without Huntington's disease. After all, we do not usually view people with life-limiting conditions as fortunate for being unlikely to outlive their peers. Whatever benefit is attached to being spared the experience of mourning one's family and friends, it is dwarfed by the great misfortune of a reduced life expectancy.

The germline cure for Huntington's disease in the isolated Huntington's community I have described is comparable to the germline lifespan extension that Robertson describes, except that the former is a case of therapy and the latter is-as framed by Robertson herselfenhancement. If the latter is less ethical than the former, then this ethical difference depends on the claim that enhancement is ethically more problematic than therapy. This is not an uncommon claim; it is one that many people have defended. However, it is not one that Robertson wishes to use; she claims, instead, to adopt a 'utilitarian model which requires that the benefits and harms of a proposition be evaluated and weighed against one another'.

Other highlights of this issue include $\mathrm{F}$ M Kamm's article considering how medical professionals can best balance patient needs and other considerations when offering end-of-life care and advanced care for chronic conditions. Her article is accompanied by commentaries from Dominic Wilkinson, Robert D Truog and Yael Schenker, to all of which Professor Kamm responds. Our viewpoint article this month is by Tom Humphries and colleagues, who confront the attitude of many healthcare professionals that learning a sign language can be harmful to children. Professor Humphries and colleagues argue that this attitude is based on prejudice, and they call for the relevant healthcare professionals to be educated accordingly.

\section{Contributors None.}

\section{Competing interests None declared.}

Provenance and peer review Not commissioned; internally peer reviewed.

(C) Article author(s) (or their employer(s) unless otherwise stated in the text of the article) 2017. All rights reserved. No commercial use is permitted unless otherwise expressly granted. 